\title{
Bisflavonoids fraction from Araucaria bidwilli Hook., reverses hyperlipidemia induced atherosclerosis in high-fat diet induced hyperlipidemia
}

\author{
Rahimullah Siddiqui ${ }^{1}$, Haja Nazeer Ahamed $^{2^{*}}$ (D) and Ismail Yusuff ${ }^{2}$
}

\begin{abstract}
Background: Hyperlipidemia is a major cause for atherosclerosis which is a frontline cause for mortality in the world. Bisflavonoids are dimeric flavonoids abundant in few medicinal herbs with various pharmacological effects. However, in vivo anti-hyperlipidemic role of bisflavonoids (BFR) is limited. The present investigation is aimed to study BFR from the leaf extract of Araucaria bidwillii Hook. in rat model of hyperlipidemia.

Results: Administration of HFD was significantly $(p<0.0001)$ shown to increase total cholesterol (TC), low-density lipoprotein (LDL), and triglycerides (TG) associated with decrease in HDL. BFR at two doses significantly decreased TC, LDL, and TG in HFD-fed rats. In addition, BFR significantly $(p<0.0001)$ decreased the MDA and significantly $(p<0.0001)$ increased the impaired anti-oxidant enzyme SOD and CAT in heart tissue induced by HFD. Further, 28 days administration of BFR significantly $(p<0.001)$ decreased HFD-induced aortic wall thickness.
\end{abstract}

Conclusion: It can be concluded that bisflavonoids from A. bidwillii Hook. leaf extract administered to high fat-fed rats showed beneficial anti-hyperlipidemic effect by reducing lipid profiles and protecting the heart tissue from oxidative stress.

Keywords: Araucaria bidwillii, Lipoproteins, Atherosclerotic plaques, Oxidative stress marker, Anti-oxidant enzymes

\section{Background}

Hyperlipidemia is a condition in which there is an elevated level of lipids and lipoproteins in the blood. It is a frontline major cause for atherosclerosis associated with morbidity and mortality in Asian countries [1]. Epidemiological studies have clearly emphasized that the significant role of circulation bad cholesterol including low-density lipoprotein (LDL) is associated with atherosclerosis [2, 3]. Consumption of high-fat diets, living sedentary lifestyle, and lack of exercise are important factors in the pathogenesis and progression of coronary artery disease [4]. Medicinal plant extracts and their

\footnotetext{
* Correspondence: haja@crescent.education

${ }^{2}$ Crescent School of Pharmacy, B.S. Abdur Rahman Crescent Institute of Science and Technology, Seethakathi Estate, GST Road, Vandalur, Chennai 600048, India

Full list of author information is available at the end of the article
}

bioactive constituents have been shown to possess various biological effects. In particular, polyphenolic phytoconstituents such as flavonoids and flavones have been shown to possess anti-hyperlipidemia potential in in vitro and in vivo experiments [5-7]. In particular, mono-flavonoids from plant extracts have been shown to inhibit oxidation of LDL and reduce triglyceride level in high-fat diet-induced hyperlipidemia $[8,9]$. The antiatherogenic effect of mono-flavonoids such as quercetin, resveratrol, and naringenin has shown the reduction of atherosclerotic plaques in rodent model of hyperlipidemia and atherosclerosis [10-12]. On the contrary, bisflavanoids are dimeric species of flavonoids which occur quite abundantly in some plant species. For example, the genus Hypericum contains amentoflavone which is known for various pharmacological properties [13]. The plant genus Araucaria belongs to the Araucariaceae 
family and traditionally has been used for amenorrhea [14]. It has a rich source of bisflavanoids which have been isolated and characterized earlier $[15,16]$. The leaf extract of Araucaria bidwillii Hook. has been shown to possess analgesic and anti-inflammatory effect [17] and cytotoxic effect against various cancer cell lines [18]. Our previous investigation on bisflavonoids separated from the ethyl acetate fraction has shown neuroprotective effect through anti-oxidant mechanism in rat model of oxidative stress [19]. There is no investigation regarding anti-hyperlipidemic effect of bisflavanoids from Araucaria bidwillii Hook. leaves which have been reported. Therefore, the evaluation of anti-hyperlipidemic potential of bisflavonoids fraction may have a valueadded biological effect and it may have a source for natural anti-hyperlipidemic and nutraceutical. This present investigation was aimed to investigate the antihyperlipidemic effect of bisflavonoids separated from the plant Araucaria bidwillii Hook., in high-fat diet-induced hyperlipidemia in rats.

\section{Methods}

\section{Chemicals}

Adrenaline bitartrate, thiobarbituric acid (TBA), and atorvastatin were from Sigma-Aldrich Co., MO, USA. Cholesterol and egg yolk powder were purchased from Hi Media Laboratories, Mumbai. The organic solvents, chemicals, and reagents were purchased from HIME DIA, Mumbai.

\section{Plant collection and authentication}

Fresh Araucaria bidwillii Hook. leaves were collected and authenticated from Government Botanical Garden, Udhagamandalam, India. It was authenticated by Botanical Survey of India, Coimbatore, Tamil Nadu. A voucher specimen (VCP/PCOL/2008-02) of this plant material has been retained in our school for further reference.

\section{Extraction of Araucaria bidwillii leaves}

The shed dried leaves weighing around $1 \mathrm{~kg}$ were coarsely powdered and macerated with $95 \% \mathrm{v} / \mathrm{v}$ of ethanol. The extract was evaporated by rotary vacuum evaporator and freeze-dried. Percentage yield of the alcoholic extract was found to be $25.5 \% \mathrm{w} / \mathrm{w}$.

\section{Separation of bisflavanoids' fraction}

The separation of bisflavanoids (BFR) was carried out by previously described method $[15,16]$. The resultant alcoholic extract was successively reflexing with hexane, dichloromethane, and ethyl acetate until the appearance of colorless solvents. The resultant residue was washed with boiling water, and the final insoluble yellow residue was dissolved in ethanol which showed confirmative test for flavonoids.

\section{Isolation of bisflavonoids by column chromatography}

The concentrated bisflavonoids' fraction (1 $\mathrm{g}$ ) was subjected to column chromatography over silica gel column and eluted with gradients of n-hexane and ethyl EtOAc system with increasing proportion to get 72 fractions. Fraction 26-45 with similar $R_{f}$ value were labelled as fraction $\mathrm{A}$ and its was evoparated under pressure to obtain compound 1. Fractions 50-63 with similar $R_{f}$ value were labeled as fraction $B$ which was evaporated which yield compound $2(33 \mathrm{mg})$. The spectral data of compounds 1 and 2 were compared with published literature $[15,16]$.

\section{Preparation of high-fat diet and induction of atherosclerosis in rats}

The modified high-fat diet was freshly prepared as per the method [20]. The diet contains wheat powder $(50 \mathrm{~g} / 100$ $\mathrm{g})$, yellow corn $(10 \mathrm{~g} / 100 \mathrm{~g})$, barley powder $(1 \mathrm{~g} / 100 \mathrm{~g})$, skimmed milk power $(20 \mathrm{~g} / 100 \mathrm{~g})$, calcium chloride $(4 \mathrm{~g} /$ $100 \mathrm{~g})$, salt $(1 \mathrm{~g} / 100 \mathrm{~g})$, oil $(7 \mathrm{~g} / 100 \mathrm{~g})$, egg yolk powder (6 $\mathrm{g} / 100 \mathrm{~g})$, and vitamin B12 $(1 \mathrm{~g} / 100 \mathrm{~g})$. Thirty male Sprague-Dawley rats about $150-200 \mathrm{~g}$ were divided into five groups. Group I rats were the control group and were fed with normal pellet chow ad libitum. Group II rats were fed with HFD. Group III rats were fed with HFD and BFR $100 \mathrm{mg} / \mathrm{kg}$ per oral route. Group IV rats were fed with high-fat diet and BFR $200 \mathrm{mg} / \mathrm{kg}$ per oral route. The two doses of BFR (100 and $200 \mathrm{mg} / \mathrm{kg}$ ) were chosen based on our previous per oral toxicity studies and the effect of $B F R$ in rat model of oxidative stress model [19]. Group V rats were fed with high-fat diet and atorvastatin $5 \mathrm{mg} / \mathrm{kg}$ per oral route. The high-fat diet and drugs were administered for 28 days ad libitum. Experiments on animals were performed based on animal ethics guidelines of IAEC (290/ CPCSEA/12.12.2000/PH07).

\section{Body weight measurement}

The body weight of the rats was measured on the 1st, 7th, 14th, 21st, and 28th day using animal weighing scale.

\section{Biochemical estimation}

At the end of the experiment, rats were sacrificed by carbon dioxide euthanasia, $2 \mathrm{ml}$ blood was collected from cardiac puncture, and serum was separated and assayed for lipid profile using standard biochemical (Randox Laboratory) assay kit.

\section{Measurement of oxidative stress and anti-oxidant markers}

Rat heart was collected for estimation of oxidative stress enzymes and anti-oxidants. Rat heart was homogenized 
with RIPA buffer (50 mM pH 7.8). The homogenate was divided into two equal volumes. The first volume of the homogenate was centrifuged at $1000 \mathrm{rpm}$ (REMI CM12) at $4{ }^{\circ} \mathrm{C}$, and the supernatant was divided into two equal volumes. The first portion of the supernatant was used for malonaldehyde assay. The remaining supernatant was used for anti-oxidant marker assay after centrifuging at 12,000 rpm (REMI CM-12) at $4{ }^{\circ} \mathrm{C}$ for 15 min. Protein was assayed by established method [21].

\section{Assay of malonaldehyde}

Malonaldehyde (MDA) was measured by already established method [22]. $0.1 \mathrm{ml}$ of tissue homogenate was mixed with $20 \%$ acetic acid $(1.5 \mathrm{ml})$, thiobarbituric acid, and sodium dodecyl sulphate $(0.2 \mathrm{ml})$. It was heated at $100^{\circ} \mathrm{C}$ for $60 \mathrm{~min}$ and cooled. Further, it was mixed with n-butanol-pyridine-water mixture and centrifuged. The organic layer was withdrawn, and absorbance was measured at $532 \mathrm{~nm}$.

\section{Assay of superoxide dismutase}

Superoxide dismutase (SOD) was assayed by standard protocol [23]. Sodium carbonate $(2.8 \mathrm{ml}$ of $0.05 \mathrm{mM}$ buffer), $100 \mu \mathrm{l}$ of EDTA, and $20 \mu \mathrm{l}$ of tissue homogenate were incubated at $30{ }^{\circ} \mathrm{C}$ for $45 \mathrm{~min}$. Adrenaline $(100 \mu \mathrm{l})$ was added, and absorbance was read at $480 \mathrm{~nm}$ for $8-12 \mathrm{~min}$.

\section{Assay of catalase}

Catalase (CAT) assay, $2.25 \mathrm{ml}$ of phosphate buffer (65 $\mathrm{mM}$ ), and $100 \mu \mathrm{l}$ of homogenate were incubated at $25^{\circ} \mathrm{C}$ for $30 \mathrm{~min} .0 .650 \mathrm{ml}$ of hydrogen peroxide was mixed with homogenate, and the absorption was read at $240 \mathrm{~nm}$ [24].

\section{Histology of aorta}

At the end of the experiment, about $1 \mathrm{~cm}$ of rat aorta was transferred into buffer neutral formalin. The tissue was fixed for $24 \mathrm{~h}$ and dehydrated with gradient alcohol, made transparent with xylene solution. The tissue was blocked with paraffin, and sections of 5-10 $\mu \mathrm{m}$ thickness were prepared. The sections were then dewaxed with $x y-$ lene, sequentially exposed to high-to-low concentration of alcohol, washed with distilled water, hematoxylin and eosin stained, dehydrated, made transparent, and fixed. The aortic wall thickness was observed under a microscope [25].

\section{Statistical analysis}

Data were expressed as mean \pm SD. Data in each group were analyzed by two-way ANOVA (body weight parameter) as well as one-way ANOVA followed by post hoc analysis-Tukey's multiple comparison test using GraphPad Prism statistical software, USA. $p<0.05$ is considered as statistically significant.

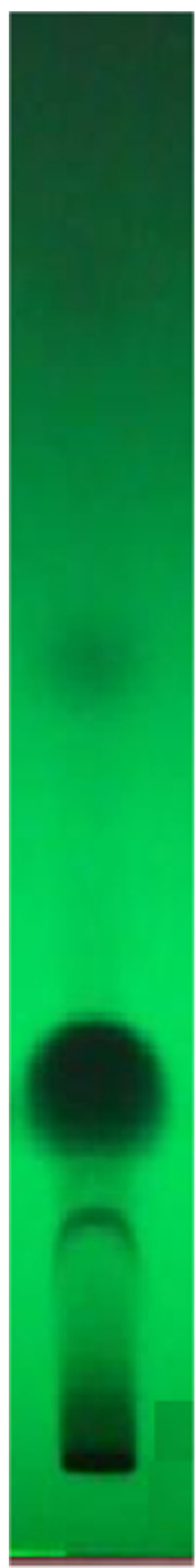

Fig. 1 TLC of crude fraction of BFR 


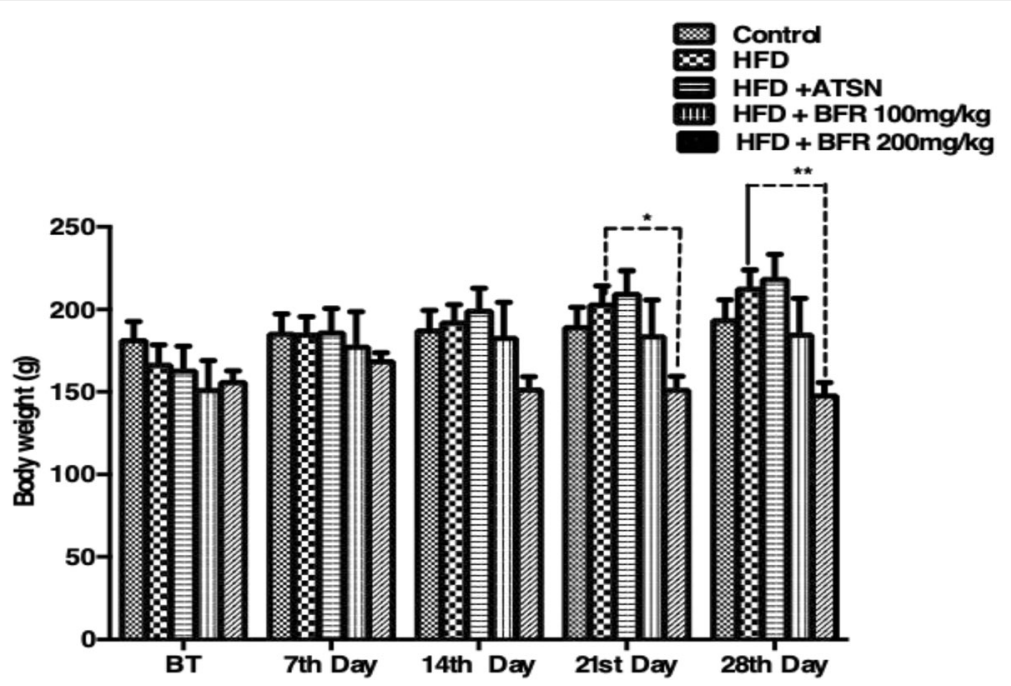

Fig. 2 Effect of BFR and ATSN in body weight of high-fat diet-fed rats. Data were expressed as mean \pm SD. Comparison made between HFD vs control and HFD + ATSN vs HFD group, HFD + BFR vs HFD. Statistical significance at ${ }^{*} p<0.05$ and ${ }^{* *} p<0.01$

\section{Results}

\section{Phytochemical analysis of bisflavonoids}

The TLC of the bisflavonoids' crude fraction was carried out using toluene-ethyl acetate-formic acid (4:5:1) (Fig. 1). The TLC plate was developed with natural product-polyethylene glycol reagent. The results from TLC plate for BFR revealed the presence of various spots with different $R_{f}$ values. The $R^{f}$ values (0.16 to 0.61$)$ were compared with the earlier literature reported with various bisflavonoids [19]. The spectral data of compound 1 (methylcupressuflavone) is yellow crystalline powder with $\mathrm{m} / \mathrm{z}$ which was 570.52 (M, 100). IR: 3247.23, 2948.17, 2802.22, 1792.45, 1673.34, 1600.71-1720.31, 1282.63, 1158.62, 917.54, and 724.33. NMR: 13.40-13.24 (2H, s), 9.22$9.51(\mathrm{H}, \mathrm{d}), 7.53-7.63(2 \mathrm{H}, \mathrm{q}), 6.83-6.89(2 \mathrm{H}, \mathrm{t}), 6.74-6.53(\mathrm{H}$, $\mathrm{m})$, 3.33-3.95 (H, m), and 2.15-2.91 (m, benzylic $\mathrm{CH})$. Compound 2 (tetrahydroamentoflavone) is pale yellow amorphous powder with $\mathrm{m} / \mathrm{z} 542.41$ (M, 100\%). IR: 3275.61, 2902.32, 1880.62, 1603.29-1880.62, 1251.14, 1158.68, 1158.69, and 741.64. NMR: 12.38-12.17 (H, s), $10.80(\mathrm{H}, \mathrm{s}), 7.33-7.35(2 \mathrm{H}$, d), 7.20-7.32 (2H, d), 6.82-6.85 (2H, d), $5.88(\mathrm{H}, \mathrm{s}), 3.91-4.06$ $(\mathrm{H}, \mathrm{m})$, and $3.11-3.36(\mathrm{~m}$, benzylic $\mathrm{CH})$.

\section{Effect of ATSN and BFR on body weight}

Effect of ATSN and BFR on body weight and lipid profile of the normal diet- and high-fat diet-treated rats is shown in Figs. 2 and 3a-d. HFD administration did not affect the body weight significantly. However, reduced body weight was observed in the BFR $(200 \mathrm{mg} / \mathrm{kg})$ treated HFD group at 21st $(p<0.01)$ and 28th $(p<$ $0.001)$ days.

\section{Effect of ATSN and BFR on lipid profile}

High-fat diet administration had significantly $(p<0.01)$ increased the total cholesterol (TC) and triglyceride
(TG) level indicating hypercholesterolemia and hypertriglyceridemia in rats compared with normal TC and TG level in the control group (Fig. 3a, b). Antihyperlipidemic effect was observed in the HFD and BFR treatment group as evidenced by significant decrease $(p$ $<0.05$ ) in TC, TG, and low-density lipoprotein (LDL) level compared with the high-fat diet-treated group. The effect of BFR in decreasing elevated lipid profile was dose dependent (Fig. 3a-c).

In addition, there was a significant decrease $(p<0.05)$ in high-density lipoprotein (HDL) in high-fat diet-fed rats than the normal diet-fed control group. BFR administration at the dose of $200 \mathrm{mg} / \mathrm{kg}$ significantly $(p<0.05)$ increased the HDL level as compared with HFD-fed rats. ASTN administration also showed a significant $(p<$ 0.05 ) effect on lipid profiles in decreasing TC, TG, and LDL and $(p<0.01)$ increasing HDL of the high-fat dietgiven rats compared with the high fat-treated control group (Fig. 3d).

\section{Effect of ATSN and BFR on MDA and anti-oxidant enzymes}

Effect of ATSN and BFR on MDA level in the heart of HFD-fed rats is shown in Figs. 4, 5, and 6. High-fat diet administration had significantly $(p<0.0001)$ elevated the rat heart MDA level pointing oxidative stress due hyperlipidemia. BFR significantly reversed $(p<0.001)$ the elevated MDA level in the HFD-treated group compared with the normal diet-treated group. Likewise, ATSN at the dose of $5 \mathrm{mg} / \mathrm{kg}$ has shown a significant decrease ( $p$ $<0.0001$ ) in MDA level as compared with the high fattreated control group. As shown in Fig. 5, significantly $(p<0.0001)$ decreased SOD level was observed in highfat diet-administered rats. BFR administration 

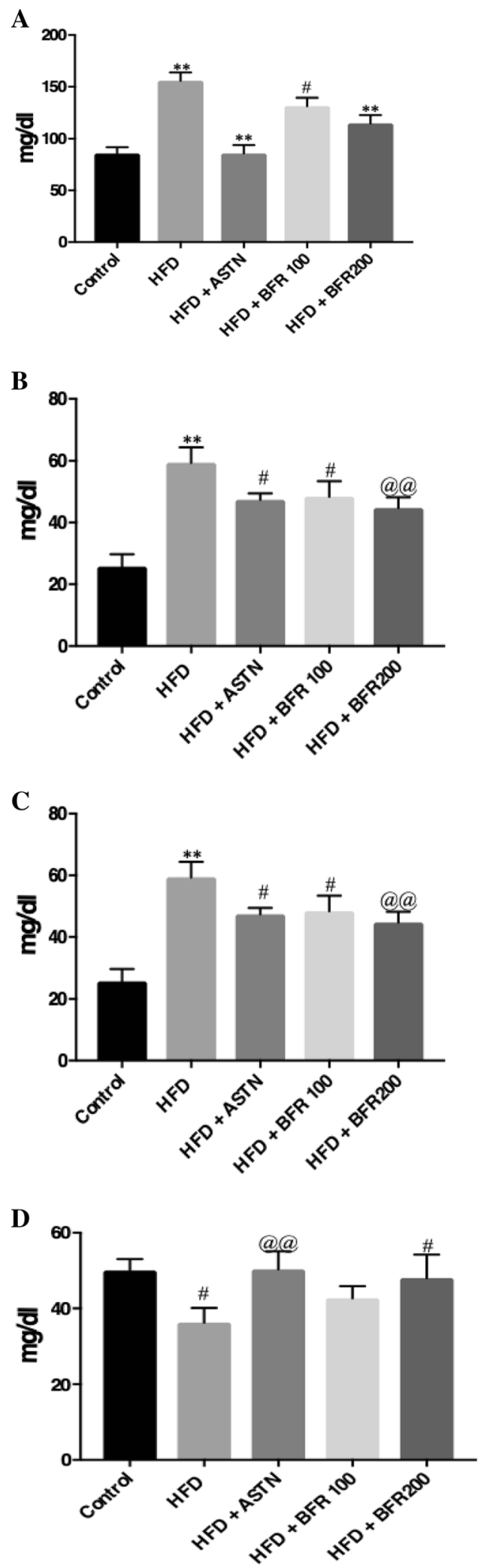

Fig. 3 a Effect of BFR and ATSN in total cholesterol level of the high-fat diet-fed rats. Data were expressed as mean \pm SD.

Comparison made between HFD vs control and HFD + ATSN vs HFD group, HFD + BFR vs HFD. Statistical significance at ${ }^{\#} p<0.05$ and ${ }^{* *} p<0.01$. $\mathbf{b}$ Effect of BFR and ATSN in low-density lipoprotein (LDL) level of the high-fat diet-fed rats. Data were expressed as mean \pm SD. Comparison made between HFD vs control and HFD + ATSN vs HFD group, HFD + BFR vs HFD. Statistical significance at ${ }^{\#} p$ $<0.05,{ }^{@}{ }^{@} p<0.01$, and ${ }^{* *} p<0.01$. c Effect of BFR and ATSN in triglyceride (TG) level of the high-fat diet-fed rats. Data were expressed as mean \pm SD. Comparison made between HFD vs control and HFD + ATSN vs HFD group, HFD + BFR vs HFD.

Statistical significance at ${ }^{*} p<0.05$, $@ p<0.01$ and ${ }^{* *} p<0.01$. d Effect of BFR and ATSN in high-density lipoprotein (HDL) level of the high-fat diet-fed rats. Data were expressed as mean \pm SD.

Comparison made between HFD vs control and HFD + ATSN vs HFD group, HFD + BFR vs HFD. Statistical significance at ${ }^{\#} p<0.05$ and ${ }^{@} p<0.01$

significantly $(p<0.001)$ elevated the anti-oxidant SOD level; the anti-oxidant effect of BFR was dose dependent. In addition, ATSN $(p<0.001)$ for 28 days to HFD-fed rats showed a significant increase in SOD level compared with the high fat-treated control group. Likewise, rats that were ingested with high-fat meal showed a significant decrease $(p<0.0001)$ in catalase compared with the control group treated rats fed with normal diet. Administration of ATSN and BFR significantly $(p<0.0001)$ increased the CAT level compared with high-fat diet rat fed CAT level.

\section{Histopathological examination of rat aorta}

Histopathological examination of high fat-fed rat aorta showed the accumulation of atheromatous plaque in subendothelial portion of the aorta as compared to normal diet-fed rat aorta (Fig. 7). There is a significant increase in aortic thickness $(p<0.0001)$ in the HFDtreated group (Fig. 8b) when compared with the normal feed-fed group (Fig. 8a). Administration of BFR at 200 mg (Fig. 8d) significantly $(p<0.05)$ reduced the high-fat diet-induced aortic thickness when compared with the high-fat diet-fed rat group (Fig. 8b).

\section{Discussion}

Herbal extracts with various bioactive phytoconstituents have been shown to exert beneficial role in reversing hyperlipidemia-induced oxidative stress [26]. Consumption of high-fat diet can cause hyperlipidemia which is a common cause for atherosclerosis, and prevalence of atherosclerosis in young adults has been increased in developing countries [27]. The A. bidwilli Hook. leaf extract has been used traditionally for various illnesses associated with oxidative stress. Our previous work on comparative free radical scavenging ability and in vivo neuroprotective effect of bisflavonoid-rich fraction in rat model of oxidative stress confirmed the in vitro and 


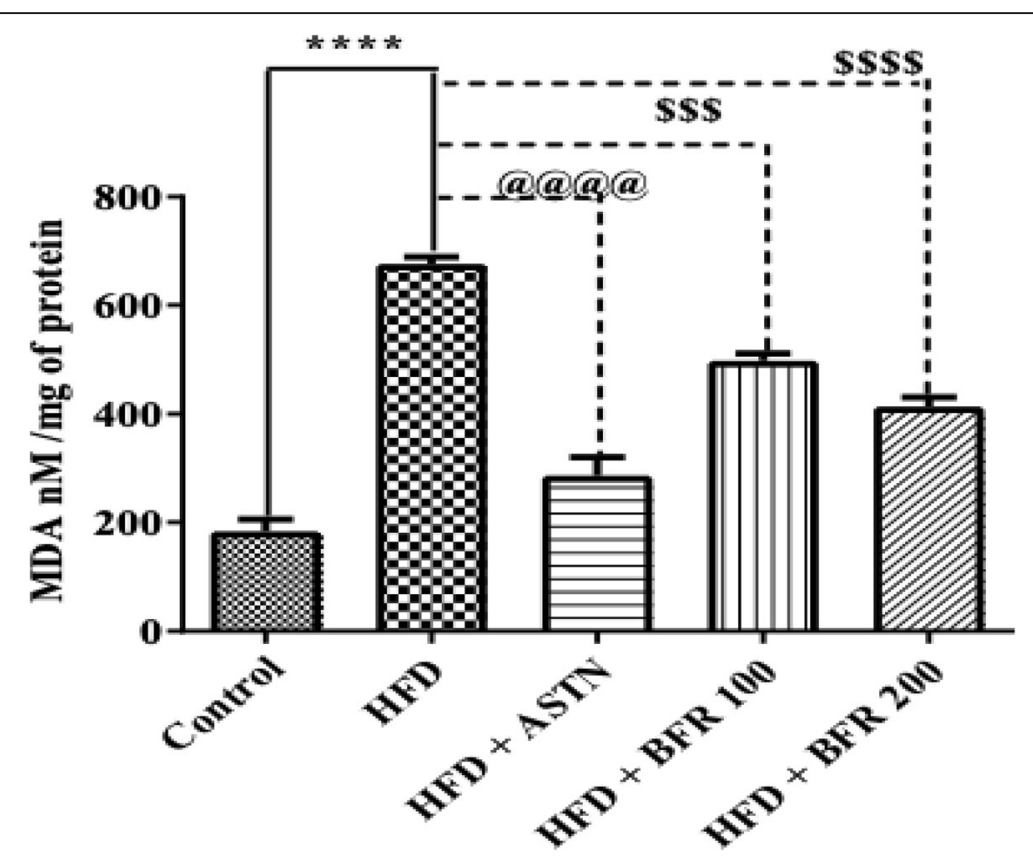

Fig. 4 Effect of BFR and ATSN in rat heart MDA level of high-fat diet-fed rats. Data were expressed as mean \pm SD. Comparison made between HFD vs control and HFD + ATSN vs HFD group, HFD + BFR vs HFD. Statistical significance at ***.@@@@ $p<0.0001$ and ${ }^{\$ \$} p<0.001$

in vivo bioactivity of the fraction. This prompted us to investigate the effect of crude bisflavonoids' fraction in experimentally induced hyperlipidemia. In this study, rats fed with atherogenic diet for 4 weeks continuously resulted in impaired lipid profile. This is due to altered transport and metabolism of total cholesterol and triglycerides in the rat plasma. It has been shown by various authors that the replacement of normal diet with high-fat diet to rats develops hyperlipidemia $[28,29]$. On the other hand, atheromatous plaque deposition in the rat aorta is due to supplementation of atherogenic diet continuously for 4 weeks and altered blood lipoprotein profiles. Previous studies have shown that significant increase in body fat composition in rats was associated with high-fat diet

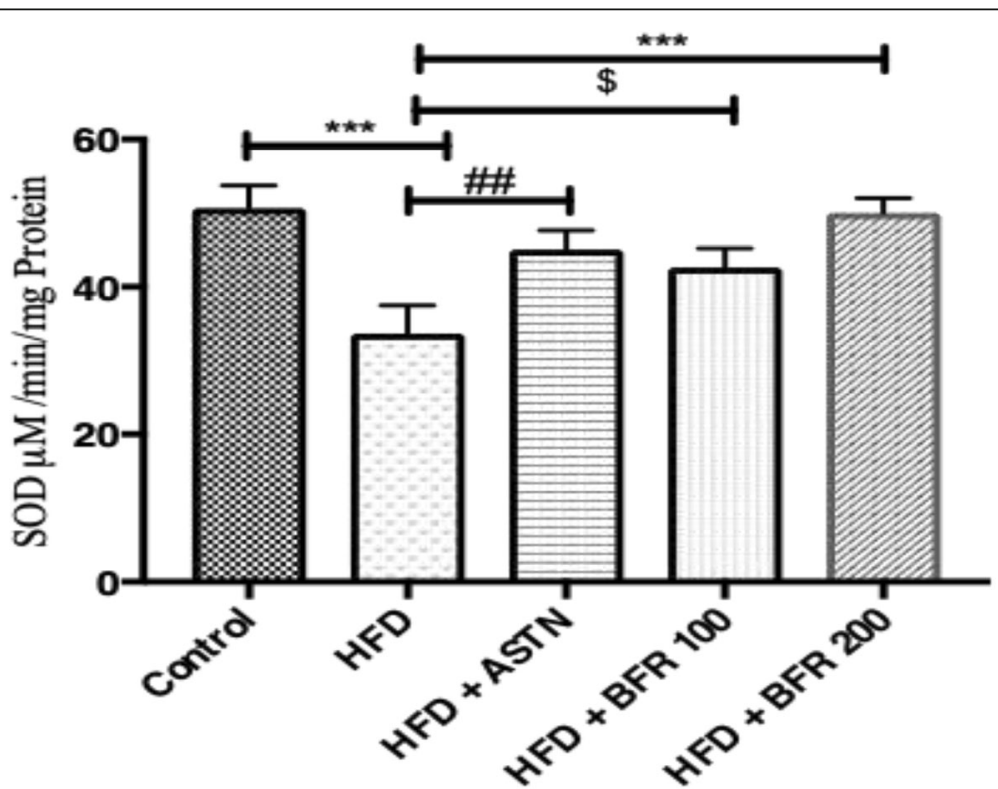

Fig. 5 Effect of BFR and ATSN in heart SOD level of high-fat diet-fed rats. Data were expressed as mean \pm SD. Comparison made between HFD vs control and HFD + ATSN vs HFD group, HFD + BFR vs HFD. Statistical significance at ${ }^{\$} p<0.05$, ${ }^{\# \#} p<0.001$, and ${ }^{* * *} p<0.001$ 


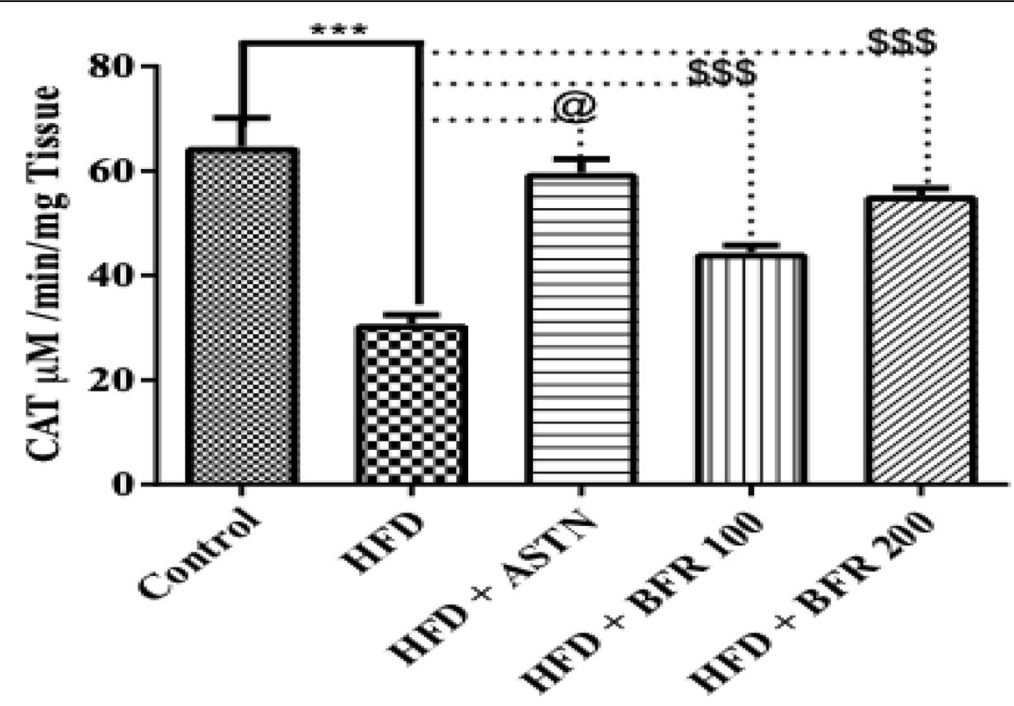

Fig. 6 Effect of BFR and ATSN in heart catalase level of high-fat diet-fed rat. Data were expressed as mean \pm SD. Comparison made between HFD vs control and HFD + ATSN vs HFD group, HFD + BFR vs HFD. Statistical significance at ${ }^{@ @ @, * * *, \$ \$ \$} p<0.001$

consumption in rats [30, 31]. However, our results showed that high fat did not affect the body weight through the entire period of high-fat diet administration. This insignificant body weight change may be due to duration of high-fat diet administration. Interestingly, the BFR-treated group had shown decreased body weight at the 21st and 28th day which suggests the possible interaction of BFR in exogenous absorption, transport, and storage of excess cholesterol and free fatty acids derived from atherogenic diet.

It is well known that plant-derived bioflavonoids with special reference to mono-flavonoids and flavones exhibit anti-hyperlipidemic effect in in vivo and in vitro model, and the beneficial effect of flavonoids on cholesterol transport, LDL, and HDL metabolism has been reviewed recently [32]. The mono-flavones like

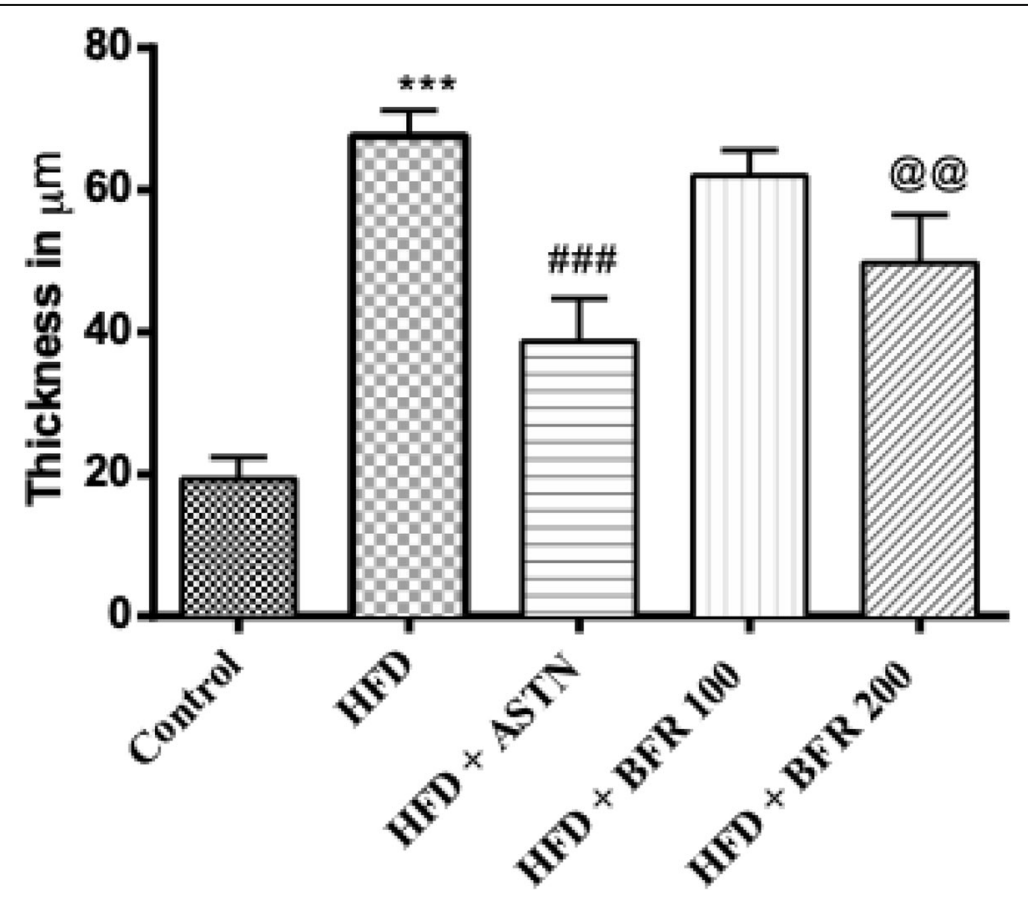

Fig. 7 Effect of BFR and ATSN in aortic wall thickness of high-fat diet-fed rats. Data were expressed as mean \pm SD. Comparison made between

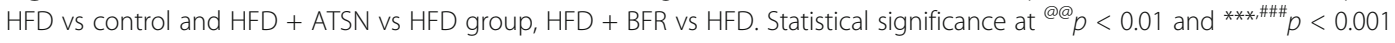



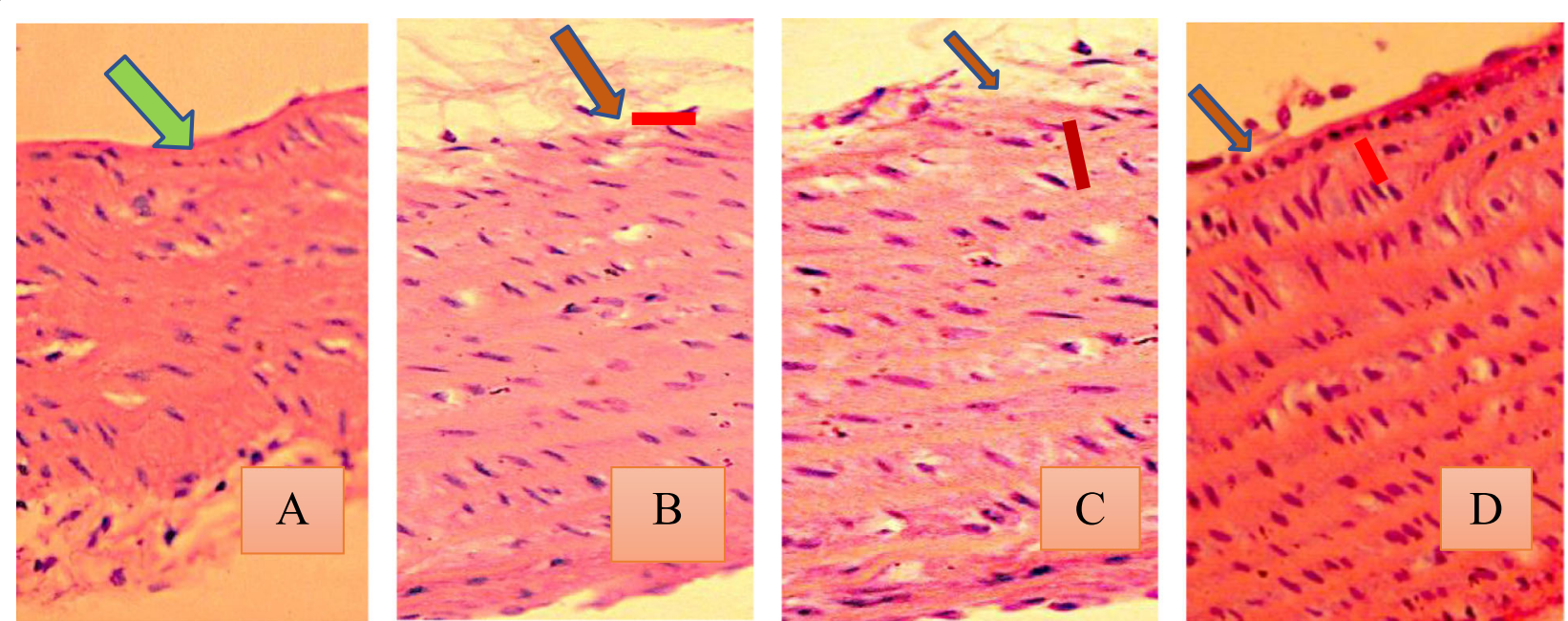

Fig. 8 Histopathology of aortic wall of normal and high-fat diet-fed rats treated with BFR and ATSN. a Normal aorta (magnification $\times 40$ ). $\mathbf{b}$ Highfat diet fed (magnification $\times 40$ ). c ATSN treated (magnification $\times$ 40). d BFR $200 \mathrm{mg} / \mathrm{kg}$ (magnification $\times$ 40). Green arrow and red arrow represent the normal and altered morphology of the aorta layer. Red thick line/bar represents the wall thickness of the aorta layer of normal and BFR, BFR + ATSN BFR treated group

hesperetin and naringenin have been shown to affect cholesterol metabolism by inhibiting endogenous pathway by affecting hepatic production of apo B containing VLDL and LDL in vitro [33-35] and in vivo [36]. In another study, catechins have been shown to facilitate the LDL receptor binding activity in HepG2 cell lines through upregulation of sterol regulated element binding protein (SREBP-1) [37]. It has been reported that monoflavonoids from various medicinal plants affect the lipoprotein lipase (LPL) activity in muscle and adipose tissue of mice and thereby inhibit the conversion and deposition of triglycerides in tissues [38, 39]. The bisflavanoids of Garcinia kola seed namely kolavarin A and B showed hypolipidemic effect in the experimental rat model of hyperlipidemia [40, 41]. The observed anti-hyperlipidemic potential of bisflavonoids' (BFR) fraction may be attributed to reduce the lipid absorption from intestine or increase the hepatic metabolism and clearance of lipoproteins.

It is well known that increase in blood cholesterol and triglycerides can generate reactive oxygen species (ROS) [42]. Further, increased LDL-C is associated with oxidative modification of LDL, overproduction of lipid peroxidation, and oxidative stress [43]. Increased MDA and decreased anti-oxidant enzymes in rat heart confirm the oxidative stress, and this impaired anti-oxidant defense was remarkably reversed by BFR which may be attributed to direct scavenging of lipid peroxidation product. The anti-lipid peroxidation mechanism of flavonol through glycoside linkage [44] and interaction of aglycone moiety $[45,46]$ have been reported. The impaired anti-oxidant enzymes such as SOD and CAT were corrected by BFR suggesting in vivo anti-oxidant enhancing capacity of BFR in high-fat diet-induced oxidative stress.
This in vivo anti-lipid peroxidation and anti-oxidant effect was aligned with the neuroprotective potential of BFR in the rat brain following bilateral common carotid artery occlusion-induced oxidative stress. Furthermore, the histopathological investigation of rat aorta showed that attenuation of atheromatous plaque deposition in high-fat diet-fed rats suggests anti-atherogenic effect. Results from our study showed that the per oral administration bisflavonoids' fraction from A. bidwilli Hook. leaf extract had reversed the atherogenic diet-induced hypercholesterolemia and hypertriglyceridemia in rats. This effect was associated with attenuation of oxidative stress and atherosclerosis by decreased deposition of atheromatous plaque in rat aorta and increased antioxidant profiles in the plasma. The anti-hyperlipidemic effect of BFR is may be due to its putative role in exogenous transport of the dietary lipids and inhibition of LDL oxidation and anti-oxidant effect in in vivo.

\section{Conclusion}

It can be concluded that bisflavonoids' fraction from $A$. bidwillii Hook. leaf extract administered to high fat-fed rats showed anti-hyperlipidemic effect by reducing blood cholesterol, triglycerides, and LDL level and protecting the heart tissue from oxidative stress.

\section{Abbreviations}

BFR: Bisflavonoids; HDF: High-fat diet; TC: Total cholesterol; LDL: Low-density lipoprotein; MDA: Malondialdehyde; SOD: Superoxide dismutase; CAT: Catalase; TBA: Thiobarbituric acid; ATSN: Atorvastatin

\section{Acknowledgements}

The authors acknowledge Vels College of Pharmacy for providing necessary laboratory support to carry out this project during his post-graduate study in pharmacy program. 


\section{Authors' contributions}

HNA and RS designed the idea and prepared the protocol for the work. RS performed the experimental work. IU carried out the histopathological interpretation. RS and HNA are responsible for the data analysis. All authors read and approved the manuscript for submission.

\section{Funding}

This research did not receive any specific grant from funding agencies in the public, commercial, or non-profit sectors,

\section{Availability of data and materials}

(a) Data and material are available upon request. (b) The plant was collected from the Government Botanical Garden and authenticated by a field botanist. The plant authentication number was VCP/PCOL/2008-02.

\section{Ethics approval and consent to participate}

The preclinical in vivo experimental procedures on Sprague-Dawley rats were carried out after receiving institutional animal ethical committee approval. The approval number is as follows: 290/CPCSEA/12.12.2000/PH07.

\section{Consent for publication}

Not applicable

\section{Competing interests}

The authors declare that there is no competing interest.

\section{Author details}

'College of Pharmacy, Department of Pharmacology and Toxicology, Jazan University, Jazan, Kingdom of Saudi Arabia. ${ }^{2}$ Crescent School of Pharmacy, B.S. Abdur Rahman Crescent Institute of Science and Technology, Seethakathi Estate, GST Road, Vandalur, Chennai 600048, India.

Received: 5 March 2020 Accepted: 7 September 2020 Published online: 19 November 2020

\section{References}

1. Ranasinghe P, Mathangasinghe $Y$, Jayawardena R, Hills AP, Misra A (2017) Prevalence and trends of metabolic syndrome among adults in the AsiaPacific region: a systematic review. BMC Pub Heal 17:101-109

2. Sharrett AR, Ballantyne CM, Coady SA, Heiss G, Sorlie PD, Catellier D, Patsch W (2001) Coronary heart disease prediction from lipoprotein cholesterol levels, triglycerides, lipoprotein(a), apolipoproteins A-I and B, and HDL density subfractions. The atherosclerosis risk in communities (ARIC) study. Circulation 104:1108-1113

3. Assmann G, Schulte H, Von Eckardstein A (1996) Hypertriglyceridemia and elevated lipoprotein (a) are risk factors for major coronary events in middleaged men. Am J Cardiol 77:1179-1184

4. Yusuf S, Reddy S, Ounpuu S, Anand S (2001) Global burden of cardiovascular diseases part I: general considerations, the epidemiologic transition, risk factors, and impact of urbanization. Circulation 104:27462753

5. Zheng X, Zhang L, Wang W, Wu Y, Zhang Q, Feng W (2011) Anti-diabetic activity and potential mechanism of total flavonoids of Selaginella tamariscina (Beauv.) Spring in rats induced by high fat diet and low dose STZ. J Ethno Pharmacol 137(1):662-668

6. Feng L, Yu C, Ying K, Hua J, Dai X (2011) Hypolipidemic and antioxidant effects of total flavonoids of Perilla Frutescens leaves in hyperlipidemia rats induced by high-fat diet. Food Res Inter 44(1):404-409

7. Kandouli C, Cassien M, Mercier A, Delehedde C, Ricquebourg E, Stocker P, Mekaouche M, Leulmi Z, Mechakra A, Thétiot-Laurent S, Culcasi M, Pietri S (2017) Antidiabetic, antioxidant and anti-inflammatory properties of water and $n$-butanol soluble extracts from Saharian Anvillea radiata in high-fat-diet fed mice. J Ethnopharmacol 207:251-267

8. Chen CY, Milbury PE, Chung SK, Blumberg J (2007) Effect of almond skin polyphenolics and quercetin on human LDL and apolipoprotein B-100 oxidation and conformation. J Nutr Biochem 18(12):785-794

9. Rahman MA, Abdullah N, Aminudin N (2015) Antioxidative effects and inhibition of human low density lipoprotein oxidation in-vitro of polyphenolic compounds in Flammulina velutipes (Golden Needle Mushroom). Oxid Med Cell Longev:403023 https://doi.org/10.1155/ 2015/403023
10. Stefania J, Jerzy W, Krzysztof M, Mariola M, Monika B, Lidia W, Barbara G, Marek D (2005) Effect of quercetin on experimental hyperlipidemia and atherosclerosis in rabbits. Pharmacol Rep 57:604-609

11. Berrougui H, Grenier G, Loued S, Drouin G, Khalil A (2009) A new insight into resveratrol as an atheroprotective compound: inhibition of lipid peroxidation and enhancement of cholesterol efflux. Atherosclerosis 207: 420-427

12. Mulvihill EE, Assini JM, Sutherland BG et al (2010) Naringenin decreases progression of atherosclerosis by improving dyslipidemia in high-fat-fed low-density lipoprotein receptor-null mice. Arterioscler Thromb Vasc Biol 30: 742-748

13. Norhrstedt A, Butterweck V (1997) Biologically active and other chemical constituents of the herb of Hypercom perforaturm L. Pharmacopsychiatry 30 (Supp) $129-134$.

14. Aslam MS, Choudhry BA, Uzair M, ljaz AS (2013) Phytochemical and ethnopharmacological review of the genus Araucaria - review. Trop J Pharm Res 12:651-659

15. Khan NU, Ilyas M, Rahman W, Mashima T, Okigawa M, Ka-Wano N (1972) Biflavones from the leaves of Araucaria bidwillii Hook and Agathis alba foxworthy (Araucariaceae). Tetrahedron 28:5695-5698

16. Rahman W, Bhatnagar SP (1968) A new biflavonyl AC3 from Araucaria cunninghamii. Tetrahedron Lett. 9(6):675-678

17. Nazeer Ahamed KFH, Kumar V, Raja S, Mukherjee K, Rajan S, Mukherjee PK (2005) Anti-nociceptive and anti-inflammatory activity of Araucaria bidwillii Hook. Iran J Pharmacol Ther 4:105-109

18. Nazeer Ahamed KFH, Kumar V, Manikandan L, Wahile AM, Mukherjee K, Saha BP, Mukherjee PK (2005) Brine shrimp lethality and cytotoxicity assay of Araucaria bidwillii Hook, in human carcinoma cell lines. Ori Pharm Exp Med 5(1):21-28

19. Mukherjee PK, Nazeer Ahamed KFH, Kumar V, Mukherjee K, Houghton PJ (2007) Protective effect of biflavones from Araucaria bidwillii Hook in rat cerebral ischemia/reperfusion induced oxidative stress. Behav Brain Res 178(2):221-228

20. Devi R, Sharma DK (2004) Hypolipidemic effect of different extracts of Clerodendron colebrookianum Walp in normal and high-fat diet fed rats. J Ethnopharmacol 90(1):63-68

21. Lowry OH, Rosebrough NJ, Farr AL, Randall RJ (1951) Protein measurement with the folin phenol reagent. J Biol Chem 193:256-275

22. Okhawa H, Ohishi N, Yagi K (1979) Assay for lipid peroxides in animal tissues by thiobarbituric acid reaction. Ann Biochem 95:351-358

23. Saggu H, Cookey J, Dexter DA (1989) A selective increase in particulate superoxide dismutase activity in Parkinsonism. J Neurochem 53:629-697

24. Beer RF, Seizer TW (1952) A spectrophotometric method for measuring breakdown of hydrogen peroxide by catalase. J Bio Chem 195:276-287

25. Venegas-Pino DE, Banko N, Khan Ml, Shi Y, Werstuck GH (2013) Quantitative analysis and characterization of atherosclerotic lesions in the murine aortic sinus. J Vis Exp 82:50933

26. Mario K, Ton B, Stephan G (2013) The relationship between high-fat dairy consumption and obesity, cardiovascular, and metabolic disease. European J Nut 52(1):1-24

27. Bahmani M, Mirhoseini M, Shizad H, Sedighi M, Shahinfard N, RafieianKopaei M (2015) A review on promising natural agents effective on hyperlipidemia. J Evid based Complementary Altern Med 20(3):228-238

28. Ghasi S, Wobodo EN, Oofili J (2000) Hypocholesterolemic effects of crude extract of leaf of Moringa oleifera Lam in high-fat diet fed wistar rats. J Ethnopharmacol 69(1):21-25

29. Vijaimohan K, Mallika Jainu KE, Sabitha S, Subramaniyam C, Anandhan CS, Devi S (2006) Beneficial effects of alpha linolenic acid rich flaxseed oil on growth performance and hepatic cholesterol metabolism in high fat diet fed rats. Life Sci 79:448-454

30. Choo JJ (2003) Green tea reduces body fat accretion caused by high-fat diet in rats through beta-adrenoceptor activation of thermogenesis in brown adipose tissue. J Nutr Biochem 14:671-676

31. Woods SC, Seeley RJ, Rushing PA, D'Alessio D, Tso P (2003) A controlled high-fat diet induces an obese syndrome in rats. J Nutr 133:1081-1087

32. Millar CL, Duclos Q, Blesso CN (2017) Effects of dietary flavonoids on reverse cholesterol transport, HDL metabolism, and HDL function. Advances in Nutrition: An Intl Rev J 8(2):226-239

33. Ebada SS, Talaat AN, Labib RM, Mandi A, Kurtan T, Müller WEG, Singab AN, Proksch P (2017) Cytotoxic labdane diterpenes and bisflavonoid atropisomers from leaves of Araucaria bidwillii. Tetrahedron 73:3048-3055 
34. Wilcox L, Borradaile NM, de Dreu LE, Huff MW (2001) Secretion of hepatocyte apoB is inhibited by the flavonoids, naringenin and hesperetin, via reduced activity and expression of ACAT2 and MTP. J Lipid Res 42(5): 725-734

35. Kurowska EM, Manthey JA, Casaschi A, Theriault AJ (2004) Modulation of HepG2 cell net apolipoprotein B secretion by the citrus polymethoxyflavone, tangeretin. Lipids 39(2):143-151

36. Whitman SC, Hazen SL, Miller DB, Hegele RA, Heinecke JW, Huff MW (1999) Modification of type $m$ VLDL, their remnants, and VLDL from ApoEknockout mice by $\mathrm{p}$-hydroxyphenylacetaldehyde, a product of myeloperoxidase activity, causes marked cholesteryl ester accumulation in macrophages. Arterioscler Thromb Vasc Biol 19(5):1238-1249

37. Bursill C, Roach PD, Cynthia DK, Bottema CDK, Pal S (2001) Green tea upregulates the low-density lipoprotein receptor through the sterolregulated element binding protein in HepG2 liver cells. J Agric Food Chem 49(11):5639-5645

38. Fan C, Yan J, Qian Y, Wo X, Gao L (2006) Regulation of lipoprotein lipase expression by effect of hawthorn flavonoids on peroxisome proliferator response element pathway. J Pharmacol Sci 100:51-58

39. Pak-Dek MS, Abdul-Hamid A, Osman A, Soh CS (2008) Inhibitory effect of Morinda Citrifolia L. on lipoprotein lipase activity. J Food Sci 73(8):C595-C598

40. Adaramoye OA, Nwaneri VO, Anyanwu KC, Farombi EO, Emerole GO (2005) Possible anti-atherogenic effect of kolaviron (a Garcinia kola seed extract) in hypercholesterolaemic rats. Clin and Exp Pharmacol Physiol 32(1-2):40-46

41. Adejor EB, Ameh DA, James DB, Owolabi OA, Ndidi US (2016) Effects of Garcinia kola biflavonoid fractions on serum lipid profile and kidney function parameters in hyperlipidemic rats. Clin Phytosci 2:19

42. Ohara Y, Peterson TE, Harrison DG (1993) Hypercholesterolemia increases endothelial superoxide anion production. J Clin Inves 91:2546-2551

43. Liu SX, Hou FF, Guo ZJ, Nagai R, Zhang WR, Liu ZQ, Zhou ZM, Zhou M, Xie D, Wang GB, Zhang X (2006) Advanced oxidation protein products accelerate atherosclerosis through promoting oxidative stress and inflammation. Arterioscler Thromb Vasc Biol 26:1156-1162

44. Ratty AK, Das NP (1988) Effects of flavonoids on nonenzymatic lipid peroxidation: structure-activity relationship and this effect may be attributed to reducing plasma LDL level and thus it might decrease the LDL oxidation. Biochem Med Metabol Biol 39(1):69-79

45. Sugihara N, Arakawa T, Ohnishi M, Furuno K (1999) Anti- and pro-oxidative effects of flavonoids on metal-induced lipid hydroperoxide-dependent lipid peroxidation in cultured hepatocytes loaded with a-linolenic acid. Free Rad Biol Med 27(11-12):1313-1323

46. Nirmala S, Nazeer AH, Ravichandran V (2011) Comparative in-vitro study on the free radical scavenging capacity of tannins and biflavones fraction from ficus racemose Linn and Aruacaria bidwilli Hook. Int J Chemtech Res 3(3): 1440-1445

\section{Publisher's Note}

Springer Nature remains neutral with regard to jurisdictional claims in published maps and institutional affiliations.

\section{Submit your manuscript to a SpringerOpen ${ }^{\circ}$ journal and benefit from:}

- Convenient online submission

- Rigorous peer review

- Open access: articles freely available online

- High visibility within the field

- Retaining the copyright to your article

Submit your next manuscript at $\boldsymbol{\nabla}$ springeropen.com 